\title{
Mapping the Virtual in Social Sciences: On the Category of "Virtual Community"
}

\author{
Serge Proulx \\ Université du Québec à Montréal < proulx.serge@uqam.ca > \\ Guillaume Latzko-Toth \\ Université du Québec à Trois-Rivières < guillaume.latzko-toth@uqtr.ca >
}

\begin{abstract}
Lately the term "virtual" has been used more and more frequently by both scholars and journalists to refer to social phenomena and entities. Quite representative of this trend is the phrase "virtual community" which has been rapidly accepted in common language. However, its use by social scientists raises many questions. Since the words "virtual" and "community" are both polysemic, what exactly might the term "virtual community" mean? And what new kind of collectivity is it supposed to circumscribe? Doesn't it imply a sort of nostalgia for a mythical form of community, along with an idealization of face-to-face interactions? This paper attempts to offer some elements of solution to these questions by means of a critical examination of recent social science texts.
\end{abstract}

The virtual, so often praised, is becoming more and more used as a term, tending to replace the vernacular use of "the network". In so doing, it is undergoing the same variations and shifts. Like the network it is a gateway notion which serves to join opposites, to render them a single entity, in a formula which faithfully reproduces the behaviour of the contemporary network in its Internet form. - Lucien Sfezi[1]

\section{Introduction}

This article is triggered by what appears to be a growing tendency in both academic and popular discourse: recourse to the notion of the "virtual" as a way of describing social phenomena and, indeed, social realities. Particularly in recently published English-language work, but also in much that is published in French, we find the adjective attached to notions and concepts as diverse as culture, society, community, democracy, university, enterprise, territory, and geography - to cite only the most striking. Emblematic of this tendency is the rapid diffusion of the expression "virtual community" through media channels, whose pervasiveness is such that it has almost become a cliché. This naturalisation of the neologism popularized by Howard Rheingold (1993) accompanied others, such as "virtual reality" and "cyberspace". Drawing on a statistical study of the occurrence of the phrase "virtual reality" in the print media between 1988 and 1993, for example, Biocca, et al. (1995, pp. 5-6) talk of a "meteoric trajectory", seeing it as a symbol of "both our enthusiasm and ambivalence about social and cultural transformation through technology."

It is as though the discursive inflation aiming at the promotion of what Phillippe Quéau (1993) called the techniques $d u$ virtuel (virtual technologies) had stimulated the opening, or at least reopening, of vast theoretical worksites across the social sciences, including sociology, anthropology, political science, history, geography and urban studies, linguistics, literary studies, and communication, as well as philosophy (Holmes, 1997a). Virtual reality, virtual community, and social reality are the recurring themes 
of these reflections, often critiques or polemics, which propose to re-examine old problematics in light of "the virtual". Yet in comparison to the sheer volume of such writing, little work appears to have been done on the usefulness or even pertinence of constantly referring to this notion as a way of shedding light on the social field. Do said notions really offer something that was missing? If so, are they deployed appropriately? Do we not risk becoming slaves to fashion, mouthing computer science jargon preprocessed by marketing specialists? How might the notion of virtuality be articulated as a detailed description of the new social uses that are linked to the technological reticulation of human territories?

This article represents a first effort to sketch out a response to these questions, via an initial cartography of the uses of virtuality in a corpus of recent writing which, to us, appeared significant within the field of the social sciences.ii[2] The first difficulty in developing a critical approach to this corpus was that, while the various authors' definitions of the virtual relied on one another so as to be mutually reinforcing, only rarely were these definitions or their sources made explicit. Hence, most of the articles in our corpus which dealt with virtual communities defined the expression vaguely at best, deferring to a notion of virtuality that was even blurrier - to the point that it is tempting to speak of "virtuality" in the social sciences as, indeed, a virtual concept. Fernback and Thompson's observation (1995) remains pertinent: "Virtual community as a concept is still amorphous due to a lack of shared mental models about what exactly constitutes community in cyberspace."

If we have chosen to concentrate on the expression "virtual community", it is precisely because that term appears to crystallize the key misunderstandings and ambiguities that litter the linkage between social and virtual. That situates our investigation at the heart of a debate operating at several levels, because it intersects with a line of questioning which continues to haunt sociology - the very definition of community as a form of social organisation and figure of life in society. Indeed, if we return to the traditional definition for community (Gemeinschaft) formulated by Tönnies (1992 [1887]), we are confronted by a collective founded on geographic and emotional proximity, involving direct, concrete, and authentic interaction between its members. It is, then, paradoxical in the first instance to associate with "community" the qualifier "virtual", linked as it is the ideas of abstraction, illusion, and simulation.

Some have openly wondered (Tremblay, 1998) about the usefulness of coining a new concept and of the words selected to name it. What new social phenomenon is being described and illuminated? Certainly, a context in which discourses underlining the radically new character of computer communication technologies invites caution (Markley, 1996; Mosco, 1998). And the terminological haze generated by the coexistence of various related phrases often employed as synonyms-online or computer-mediated communities, electronic communities, tele- and cyber- and techno-communities, techno-sociality, and so forth-contrasted with the prudence with which certain authors tiptoe around the term "virtual communities" betrays a certain malaise.

But we have no wish to act as linguistic referees and are utterly disinterested in legitimating or denouncing how the notion of "virtual community" is used. The opposite, in fact: we believe that, beyond its intrinsic qualities or failures, the persistence of this expression - which is moving beyond the status of neologism to emerge as a field of research - may be explained precisely by its problematic character (Wilbur, 1997); similarly, its performative aspect must not be neglected. Rather than staking out a position in this debate, then, we attempt to delve into it transversally, hoping to dislodge the motivations behind, and key challenges awaiting, this recent propensity to consider the social through the dawning of the virtual.

\section{Between the Ersatz and the Sublime: Three Ways to Conjugate the Virtual}

The etymology of the adjective "virtual" brings up more ambivalence than clarification, which partly explains the wide variations in its meaning and the confusion it engenders (Wood, 1998, p. 4). Blaise Galland (1999) notesiii[3] that "the history of the term 'virtual' depends upon the social uses which we make of it." And Pierre Lévy (1995, p. 13) points out that the word comes from the medieval Latin virtualis, itself a derivation of virtus, literally "force, potential". According to the French dictionary Le Petit Robert, to be virtual is thus to "not be so except potentially"- "potentially", with regard to an actualisation which may or may not take place. In this sense, the virtual is real but "not present". Yet virtus also signifies virtue (Cadoz, 1994, p. 8; Granger, 1995) in its archaic sense of "quality" or "power". It is interesting to note that it is particularly in English-language writing that the ethical implications of this "semantic overlap 
between the terms 'virtue' and 'virtual'" are underlined (Keown, 1998, p. 76). Shawn Wilbur (1997, p. 9), for example, considers this notion of virtuality profoundly rooted in "a religious world view where power and moral goodness are united in virtue."

As Gilles-Gaston Granger (1995) and Jean-Michel Besnier (1995) explain, it is the physicomathematical sciences which, from the 18th century, helped spread the use of the word "virtual" and diversified its meaning considerably according to its field of application. Its use in mechanics, the theory of forces and of movement, refers to non-observable phenomena, but in an etiological or explanatory manner. Hence Dirac's notion of "virtual particles", so fleeting that they cannot be detected individually, yet whose influence can be statistically measured (see Iliopoulos, 1995). In other cases the virtual realities of physics are purely imaginary constructs, underscoring the idea that the empirical world is but one actualisation from within "the matrix of possible [worlds]" (Besnier, p. 6).

"Quite naturally, it is the notion of model which positively connotes that of virtual," in Besnier's summation (1995, p.13). That the model's status is ambiguous, however, is as obvious to common sense as it is to philosophers, for if it connotes a sense of "purification" or of "ideal" which underlies empirical phenomena, it can also evoke the reduction through abstraction of a richer reality. The fundamental ambiguity of the virtual may also be linked to its use in optics: an image is said to be virtual when it appears to form between a real object and a divergent lens (magnification). Unlike the real image produced by a convergent lens, the virtual image cannot be materialized on a screen, because it exists only on the retina. This "image", in other words, is but a subjective perception. It does not exist independently of the subject-spectator. To a certain extent, optics assimilates virtuality to illusion.

We see, then, the outlines of two very distinct methods of imagining the relationship between the virtual and the real in the physical sciences, each of which has influenced the epistemology of the virtual in its own manner. While the theory of forces opposes the virtual to the actual or present, two modalities of being each as "real" as the other, the theory of light—closer to ordinary intuition—opposes the virtual and the real.

It is therefore unsurprising that philosophy and the social sciences have also diverged. In these interpretations of the notion of the virtual; the "new technologies" linked to the virtual have helped both to reveal and to catalyze these divergences. Marcus Doel and David Clarke (1999) offer a particularly useful synthesis of these different thought streams, noting that "the most important error [generally committed] is the reduction of reality to actuality and virtuality to possibility: as if the actual and the virtual were the given and the pre-given, respectively" (p. 262). They continue: "it is the need to rethink space-time rather than any new-fangled technologies, which poses the most pressing challenge".

Starting from Doel's and Clarke's observations, themselves based on a vast theoretical corpus, we have retained three principal approaches to virtuality for categorising the different discourses on "virtual communities". In preparing a schematic, these approaches may be distinguished by the types of relationship they pose between the real and the virtual and by the shifts in meaning which they favour. In the first approach, the virtual is "subordinated to (...) the real" and refers to re-presentation; in other words, to the simulation and therefore the "false approximation" of reality constituted by virtual images and computergenerated virtual reality (p. 262). The latter is perceived as a "facsimile of the real" (p. 265) - a copy, but "necessarily degrade[d]" (p. 263), "a reality divorced from the world" (Slouka, 1995, p. 13), a "false reality" (Lebrun, 1996), a "simulacrum" or a "double" of the real (Baudrillard, 1981, 1996), to be considered pejoratively given the inherent "duplicity" of any duplicate (Doel \& Clarke, 1999, p. 264).

Diametrically opposed to this discourse of denigration, the second approach sees virtuality as the "resolution" of a world overwrought by imperfection as the very consequence of its presence, which is but a subset of the universe of possibilities - and therefore an unavoidable impoverishment. "In this case, the virtual is to the real as the perfect is to the imperfect", in Doel and Clarke's formulation (1999, p. 268). Those adopting this approach inverse the relationship between the virtual and actual-present invoked above. For Pierre Lévy (1995), to virtualise an entity or a process is to return to its essence, to its abstract and general being, and in so doing, to the matrix of its possible actualisations. Here, computer simulation is no longer considered a degradation but a tool for exploration, to "auscultate reality" (Weissberg, 1999, p. 49 ), even to amplify or reduce it. As for global communication networks, they emancipate human activity from the constraints of materiality, space, and time, opening onto unprecedented opportunity. In this sense, 
the virtual is "fuller" than the actual, it is "hyperreal", and the technologies of the virtual are perceived as liberatory to the extent that they offer a portal to the richness of the real: "The real world has always been marked by scarcity. On this basis, evolution figures as a painfully slow attempt to 'fill out' the world a little, and to realise a few more of its possibilities" (Doel \& Clarke, 1999, p. 267).

As we see, the two schools of thought discussed above "rest upon a strict [though fallacious] separation of the real and the virtual" (Doel \& Clarke, 1999, p. 263). We might add that each is imprinted with technological determinism, since in each case, the irruption of the virtual into the everyday coincides with technological progress. Yet we might usefully imagine a far more complex relationship between virtuality and actuality by considering the virtual as something more than the derivative of a technical apparatus: "everyday life itself is always already a virtual reality" (p. 279). The third approach we have gleaned from Doel and Clarke is thus strongly Deleuzian. It harks back to the hybridisation of the real and of the virtual, or more precisely, to the immanence of the virtual in the real and a conception of the real in which the actual and the virtual are in a circular and productive relationship. From their perpetual interaction springs a real which is in constant "creation and experimentation" (p. 280).

To better schematise this reading of contemporary discourses on virtuality, we might note that our grid oscillates between two extreme visions, the ersatz and the sublime. The first, "paranoid" (Boal, 1995, p. 9), tends to discredit the virtual as an "artificial reality", opposed somewhat naively to a "mythical" nature (Woolley, 1992, p.8). Even Brook and Boal (1995), who talk of resisting any simplistic idealisation of the "natural life", wind up calling for "resisting the virtual life", for "virtual technologies are pernicious when their simulacra of relationships are deployed societywide as substitutes for face-to-face interactions, which are inherently richer than mediated interactions" (p. viii).

The second version of the virtual is, in contrast, utopian, even euphoric (Bardini, 1996; Robins, 1996; Weissberg, 1996). It apprehends virtual worlds as the pioneers of the American Old West talked of the "frontier" (Eudes, 1996; Wilbur, 1997, p. 8), or again as the "quest for the Holy Grail" of technology (Heim, 1993, p. 124). Kevin Robins cannot resist waxing ironic in his description of these "dithyrambic discourses [...] about virtual reality" (Bardini, 1996) that participate in an ideology that typically accompanies new information and communication technologies (Breton \& Proulx, 1989):

a faith that (...) a new technology will finally and truly deliver us from the limitations and the frustrations of this imperfect world. (...) The utopian space - the Net, the Matrix - will be a nowhere-somewhere in which we shall be able to recover the meaning and the experience of community (Robins, 1996, p. 2).

Some authors do speak out against what they see as a spurious dichotomy posing virtual against real, proposing instead a third way "towards more textured understandings of the varying forms of virtuality worked through different technologies in different times and places" (Crang et al., 1999, p. 3). Similarly, Michael Ostwald (1997, p. 127) notes that "the rise in virtual technologies is a natural extension of the way in which twentieth-century urban communal spaces already constitute virtual environments." He further points out that "there is often little or no gap between the so-called 'real world' and the 'virtual world'" and consequently, declares it urgent to pay closer attention to "that zone where the boundaries between the physical and the virtual are completely blurred" (p. 128).

\section{Simulated Communities or Stimulated Communities?}

In picking up the three perspectives laid out above, we shall try and show that they underpin the principal viewpoints expressed in the literature on virtual communities. First, however, we shall dally on the context in which this notion emerged within public space.

If the origins of the expression "virtual reality" may be situated with relative precision - the term was worked out by computer engineer Jaron Lanier around 1989 (Pimentel \& Teixeira, 1993; Woolley, 1992) the origin of "virtual community" remains as nebulous as its definition. Sandy Stone (1991) attributes the moniker to a group of networking pioneers who created one of the first Bulletin Board Servicesiv[4] (BBSs), CommuniTree: "[They] had developed the idea that the BBS was a virtual community, a community that promised radical transformation of existing society and the emergence of new social forms" (p. 88). 
We might surmise that the expression "virtual community" appeared as a synthesis between, on the one hand, the growing fascination with the very word virtuality - as much in the popular imagination of engineers as in the imagination of "gurus" like Timothy Leary-and on the other hand, the term online community. The latter was introduced toward the end of the 1960s by two of the "fathers" of computermediated communication, J. C. R. Licklider and Robert W. Taylor (1968 [1990]), in a visionary text entitled "The Computer as a Communication Device", and described as follows: "they will consist of geographically separated members (...). They will be communities not of common location, but of common interest" (pp. 37-38).

In all cases, it was through the Sausolito, California-based BBS called the WELL (Whole Earth 'Lectronic Link), founded in 1985, that the notion of virtual community gained rapid notoriety (Hafner, 1997), thanks especially to the widely-discussed book written by one of its most famous members, Howard Rheingold (1993). Rheingold defined virtual communities as "social aggregations that emerge from the Net when enough people carry on those public discussions long enough, with sufficient human feeling, to form webs of personal relationships in cyberspace" (p. 5).

In another passage, he describes them more vividly, and more concretely:

People in virtual communities use words on screens to exchange pleasantries and argue, engage in intellectual discourse, conduct commerce, exchange knowledge, share emotional support, make plans, brainstorm, gossip, feud, fall in love, find friends and lose them, play games, flirt, create a little high art and a lot if idle talk. People in virtual communities do just about everything people do in real life, but we leave our bodies behind (p. 3).

Also a well-known WELL user or "member", John Perry Barlow (1995) saw the online community as an anchor - virtual or not-which might restore to the U.S. a social contract under attack from a growing nomadism: "Once again, people (...) had a place their hearts could remain as the companies they worked for shuffled their bodies around America. They could put down roots which could not be ripped out by forces of economic history. They had a collective stake. They had a community."

But the Electronic Frontier Foundation co-founder, author of a "declaration of the independence of cyberspace" (Barlow, 1996), was also inspired by the idea that virtual communities could permit civil society to re-appropriate a governmental function monopolized by an omnipresent State. In this sense, he positioned himself within a political tradition associated in the United States with Thomas Jefferson, a figure to whom Mitch Kapor, EFF's other co-founder, referred explicitlyv[5]: "Life in cyberspace seems to be shaping up exactly like Thomas Jefferson would have wanted: founded on the primacy of individual liberty and a commitment to pluralism, diversity, and community" (1993, p. 53).

For Stone (1991), the constant mention of trees in Barlow's discourse and in names like CommuniTree are significant, referring not only to the logical tree structures used in computer science, but "also the organic qualities of trees as such appropriate to the 1970s" (p. 89). As should be clear, the notion of virtual community was directly inspired by the values of the Californian counter-culture of the 1970s, presenting itself as a new federating myth capable of regenerating the communitarian dream: "The conferencees saw themselves not primarily as readers of bulletin boards or participants in a novel discourse but as agents of a new kind of social experiment" (p. 90). Stone goes on to underscore the fact that these socio-technical experiments were built upon the use of shareware software similar to what is now called "free software": "The idea of shareware, as enunciated by the many programmers who wrote shareware programs, was that the computer was a passage point for circulating concepts of community" (p. 88).

Yet Sherry Turkle (1995) picks out a significant ambiguity in these communitarian aspirations. Comparing microcomputing's first users to the first users of MUDs (Multi-User Domains) - virtual realities shared via a text-based interface-Turkle notes that where the former saw in "their relationships with the computer - building safe microworlds of transparent understanding - (...) a political metaphor" transposable to society at large in order to install "a more participatory political system", the MUD world started out quite differently: "When nearly twenty years later, another group of people has turned to computation as a resource for community building, the communities they are thinking of exist on and through the computer" (p. 243). 
Developing this idea, Turkle notes that "if the politics of virtuality means democracy online and apathy offline, there is reason for concern" (op. cit., p. 244). Her remarks highlight a distinction between virtual community and community networksvi[6]. While "virtual community" refers to social forms built upon communities of interest rather than geographic proximity, "community networks" translates citizen appropriation of interactive networks into the context of local democratic development (Schuler, 1996).

This distinction vis-à-vis virtual communities poses the problem of their "reality". What is their sociological "consistency", and especially, what is the scope of the role that such communities can play at the macro-social level? In other words, "to what extent do most virtual communities provide individuals with opportunities to contribute to the greater collectivity?" (Fernback, 1997, p. 42). A review of the three conceptions of the relationship between virtual and real noted above-representation, resolution, and hybridisation-helps establish a framework for thinking through these questions.

Let us start with representation, which conjures forth several notions. One is fiction: Margaret Morse, for example, imagines mediatised relations as "fictions of presence" (1998, p. 17) without denying them an obvious efficiency. But representation also evokes the idea of imitation, or-to slip into computers - of emulation. That is the meaning that the word "virtual" has acquired in computer science, notes Benjamin Woolley (1992, p. 58), following IBM's commercialisation in 1972 of a product called virtual memory, "a simulation (...) that is perfect in every detail, except that it might be slower than 'real' memory" (p. 60). In this sense, a virtual community might be interpreted as the "functional simulation" of community - with the accompanying danger of a certain loss of meaning in translation.

Such an idea might seem overly exaggerated. Note, however, Turkle's thesis (1995) that the "culture of simulation" has penetrated our civilization, and restructured our daily lives, as profoundly as have the computer and the television before it. She calls this process a "Disneyland effect" (p.236) that promulgates the aberrant belief in shopping malls and other recreational complexes as convincing replies to the small villages of yesteryear, with their marketplaces and church towers. That leads into a highly critical charge against virtual communities: "Is it really sensible to suggest that the way to revitalize community is to sit alone in our rooms, typing at our networked computers and filling our lives with virtual friends?" (p. 235).

Others go further, abhorring the notion that "simulacra of community" might replace "real" communities. Fernback and Thompson (1995) reproduce the remarks of Ed Schwartz, for example, advanced in an online discussion forum on the topic of "Communet": "[Computer bulletin boards] add the final mechanism needed to insure that we never talk to people beyond our immediate friends and family on a personal level about anything. The global community, linked by terminals, replaces community where we are." Frank Weinreich (1997) makes a similar argument: "I don't see that we have already gone so far that we have lost 'real' contact to each others. But the danger is imminent if we go on believing that we might constitute and run communities solely in the virtual world."

To complete the portrait, note Michael Heim's position (1993), very much inscribed in what is a dark and, ultimately, determinist vision of the virtual:

Computer communication cuts the physical face out of the communication process. (...) Even video conferencing adds only a simulation of face-to-face meeting, only a representation or an appearance of real meeting. (...) Face-to-face communication, the fleshly bond between people, supports a long-term warmth and loyalty, a sense of obligation for which the computermediated communities have not yet been tested (p. 102).

If the second, opposing approach to the virtual is that of resolution - that is, a virtuous role in which the virtual provides what the real lacks - it is easily recognized in the enthusiastic and even proselytising discourse of Rheingold (1993). Though he acknowledges an absence of critical distance triggered by ongoing immersion in the experience, he nonetheless assigns to virtual communities some "liberating potentials" (p. 4), since CMC "enables people to do things with each other in new ways, and to do altogether new kinds of things-just as telegraphs, telephones, and televisions did" (p. 6). Pierre Lévy (1997) goes further in this direction, proposing a vision which might be called promethean:

Mexican cuisine fans, Angora cat lovers, fanatics of a given programming language, or passionate readers of Heidegger, once dispersed across the planet, now have a familiar place to meet and to talk. We may therefore support the notion that so-called 'virtual communities' do in 
fact manage a veritable actualisation (by putting them in touch effectively) of human groups which existed only in potential before the coming of cyberspace (p. 154).

It is unsurprising to see this brand of discourse prophecying the dawn of a new era each time a new communications technology arrives on the scene (Carey, 1989). Indeed, in a text translating a rare skepticism on the part of its author, Barlow (1995) admits that his enthusiasm for virtual community has cooled.

That said, the conception of virtual communities as instances of liberation persists, and with it a subtler version of utopia. This conception does not restrict itself to spatio-temporal considerations, of course, and extends to gender, ethnic attachment, social class, sexual identity, and various physical conditions. In short, virtual community is seen by some authors as a means for setting individuals free of the prisons which are their bodies and, by extension, of equalizing disadvantages and emancipating social minorities (Plant, 1996; Willson, 1997), notwithstanding the statistical studies computer-mediated communication which continue to reveal significant divides in terms of social class and ethnic origin in Internet access, notably in the United States, and reports showing the persistence of gender and race indicators (Smith and Kollock, 1999), the reproduction of relations of dominance (Herring, 1993), and forms of elitism (Gimenez, 1997).

The approaches to virtual communities described here have to this point placed special emphasis on two aspects in particular: correlation between virtual communities and the emergence of computer networks, and the essentially "abstract" nature (Willson, 1997) of these communities from which bodies are absent. These two propositions are the object of a growing critique which is supported by at least three epistemological arguments. The first concerns the weak articulation between theory and fieldwork. "There have been few detailed ethnographic studies of virtual communities", lament Wellman and Gulia (1999, p. 170), while Beckers (1998) notes that "although the interest on virtual communities is large, the overall quality and depth of the research can be questioned". Smith and Kollock $(1999$, p. 16) consider that "opinion rather than analysis and evidence characterizes much of" the academic discourse on virtual communities.

The second epistemological critique of the ersatz and sublime arguments sets its sights upon the overemphasised relationship between virtuality and actuality that permeates much work on virtual communities. In this vein, Wellman and Gulia (1999) recall that:

both enthusiasts and critics of virtual community usually speak of relationships as being solely online. Their fixation on the technology leads them to ignore the abundant accounts of community ties operating both online and offline, with the Net being just one of several ways of communicating. Despite all the talk about virtual community transcending time and space sui generis, much contact is between people who see each other in person and live locally (p. 179).

Sandy Stone (1991, p. 112) broadens this perspective, suggesting that

participants in the electronic virtual communities of cyberspace live in the borderlands of both physical and virtual culture (...). Their social system includes other people, quasi people or delegated agencies that represent specific individuals, and quasi agents that represent 'intelligent' machines, clusters of people, or both.

This third figure of the virtual community is characterized by hybridity. Indeed, and this is the third epistemological critique, virtual communities may be said to transcend particular technologies or even eras. Stone distinguishes between four eras, each characterized by a typical form of "virtual community", since the formation of the first intellectual and scientific communities in the $17^{\text {th }}$ Century, through radio and television publics, and on to the Internet's MUDs. In developing this framework, Stone defines virtual communities as "incontrovertibly social spaces in which people still meet face-to-face, but under new definitions of both 'meet' and 'face'" (Stone, 1991, p. 85).

\section{Conclusion}

A close examination of current Internet events makes it difficult to avoid the conclusion that new collective forms are in the process of being invented. In these new communities, communal resources are 
framed, not simply by information, but by the very "presence" of others, be this presence abstract, mental, or paradoxically distant, to borrow a title from Jean-Louis Weissberg (1999). The virtual context of these communities might be grasped through the metaphor of a desert watering-hole, or a "passage point", in Sandy Stone's term (1991). It is a precarious pole of attraction where individuals of diverse and divergent provenances "meet", allowing "unfocused interaction" favourable to the development of collective dynamics to take form.

Unlike classical communities, which are constrained to remain bound by a promiscuity without alternatives, the commitment of electronic collectives is (generally) more fluid. The boundaries are blurred, and so, in a certain sense, their reality may be considered virtual. But let us not fool ourselves: virtuality should not be understood as a distortion of the social, but as one of its aspects, an optical effect of its growing complexity, amplified by its own technological artifacts. That, at least, is one of the ideas that we hope to have pried loose in this brief and limited review of the various uses to which the virtual might be put as a category for thinking through contemporary societies.

\section{References}

Bardini, T. (1996). Quand l'imaginaire devient réalité... virtuelle: à propos des mythes entourant les technologies du virtuel, Interface 17(6), 51-55.

Barlow, J. P. (1995, March/April). Is there a there there in cyberspace?, Utne Reader 68, 53-56, Available: http://www.eff.org/pub/Publications/John_Perry_Barlow/HTML/utne_community.html

Barlow, J. P. (1996). A declaration of the independence of cyberspace. Unpublished manuscript. Available: http://www.eff.org/pub/Publications/John_Perry_Barlow/barlow 0296.declaration

Baudrillard, J. (1981). Simulacres and simulation. Collection Débats. Paris: Kawade Shobo Shinsha.

Baudrillard, J. (1996, May 6). Écran total, Libération.

Beckers, D. (1998, November). Research on virtual communities: an empirical approach. Paper presented at the PDC '98 / CSCW '98 Workshop on Designing Across Borders: The Community Design of Community Networks, Seattle, WA. Available: http://www.swi.psy.uva.nl/usr/beckers/publications/seattle.html

Besnier, J-M. (1995). Introduction. In G. Cohen-Tannoudji (Ed). Virtualité and réalité dans les sciences. Gif-sur-Yvette, France: Editions Frontières.

Biocca, F., Kim, T., \& Levy, M. R. (1995). The vision of virtual reality. In F. Biocca \& M. R. Levy (Eds.), Communication in the age of virtual reality (pp. 3-14). Hillsdale, NJ: Lawrence Erlbaum.

Boal, I. A. (1995). A flow of monsters: Luddism and virtual technologies. In J. Brook \& I. A. Boal (Eds.), Resisting the virtual life: The culture and politics of information (pp. 3-15). San Francisco: City Lights.

Breton, P., \& Proulx, S. (1989). L'explosion de la communication: La naissance d'une nouvelle idéologie. Paris: La Découverte.

Brook, J., \& Boal, I. A. (Eds.). (1995). Resisting the virtual life: The culture and politics of information, San Francisco: City Lights.

Cadoz, C. (1994). Les réalités virtuelles. Collection Dominos. Paris: Flammarion.

Carey, J. (1989). Communication as culture. Winchester, MA: Unwin-Hyman.

Crang, M., Crang, P., \& May, J. (Eds.). (1999). Virtual geographies. Bodies, space and relations. London: Routledge.

Doel, M. A., \& Clarke, D. B. (1999). Virtual worlds: Simulation, suppletion, s(ed)uction and simulacra. In M. Crang, P. Crang, \& J. May (Eds.), Virtual geographies: Bodies, space and relations (pp. 261283). London: Routledge. 
Eudes, Y. (1996, October). Bataille pour la liberté sur les réseaux, Manière de voir, hors-série: Internet, l'extase and l'effroi, 37-41.

Fernback, J. (1997). The individual within the collective: Virtual ideology and the realization of collective principles. In S. G. Jones (Ed.), Virtual culture (36-54), Thousand Oaks, CA: Sage .

Fernback, J., \& B. Thompson. (1995, May). Virtual communities: Abort, retry, failure? Based on a paper presented at the annual congress of the International Communication Association, Albuquerque, NM. Available: http://www.well.com/user/hlr/texts/VCcivil.html

Galland, B. (1999, October). Espaces virtuels: La fin du territoire? Paper presented at the $1^{\text {er }}$ forum art et science, Le virtuel ou la conscience de l'artificiel, Institut Universitaire Kurt Bösch, Sion, Suisse.

Gimenez, M. (1997). The dialectics between the real and the virtual: The case of PSN. In J. E. Behar (Ed.), Mapping cyberspace: Social research in the electronic frontier (pp. 79-104). Oakdale, NY:

Dowling Press. Available: http://www.usyd.edu.au/su/social/papers/gimenez.htm

Granger, G-G. (1995). Le probable, le possible et le virtuel. Paris: Odile Jacob.

Hafner, K. (1997). The epic saga of The Well: The world's most influential online community (And it's not AOL), Wired 5(5), 98-142. Available: http://www.wired.com/wired/archive/5.05/ff well.html

Harvey, P-L. (1995). Cyberspace et communautique : Appropriation, réseaux, groupes virtuels. Québec: Presses de l'Université Laval.

Heim, M. (1993). The metaphysics of virtual reality. New York: Oxford University Press.

Herring, S. C. (1993). Gender and democracy in computer-mediated communication, Electronic Journal of Communication / Revue électronique de communication, 3(2). Available: http://www.cios.org/www/ejcmain.htm; http:/www.usyd.edu.au/su/social/papers/herring.txt

Holmes, D. (1997a). Introduction. In D. Holmes (Ed.), Virtual politics: Identity \& community in cyberspace (pp. 1-25). London: Sage.

Iliopoulos, J. (1995). L'invention d'une nouvelle particule. In G. Cohen-Tannoudji (Ed.), Virtualité et réalité dans les sciences. Gif-sur-Yvette, France: Editions Frontières.

Kapor, M. (1993). Where is the digital highway really heading? The case for a Jeffersonian information policy. Wired, 1.03, 53-59, 94.

Keown, D. (1998). Embodying virtue: a Buddhist perspective on virtual reality. In J. Wood (Ed.), The virtual embodied: Presence/practice/technology (pp. 76-87). London: Routledge.

Lebrun, C. (1996, November). Réel-virtuel: la confusion du sens. Futuribles, 214, 23-41.

Lévy, P. (1995). Qu'est-ce que le virtuel? Paris: La Découverte, 1995.

Lévy, P. (1997). Cyberculture: Rapport au Conseil de l'Europe dans le cadre du projet Nouvelles technologies: coopération culturelle et communication. Paris: Odile Jacob.

Licklider, J. C. R., \& R. W. Taylor. (1968). The computer as a communication device. Science and Technology, April. Republished in SRC Research Report 61, Digital Equipment Corporation, 1990. Available: ftp://ftp.digital.com/pub/DEC/SRC/research-reports/SRC-061.pdf

Markley, R. (1996). Introduction: History, theory, and virtual reality. In R. Markley (Ed.), Virtual realities and their discontent (pp. 1-10). Baltimore: Johns Hopkins Press.

Mosco, V. (1998). "Myth-ing Links: Power and community on the information highway. The Information Society 14(1), 57-62.

Morse, M. (1998). Virtualities: Television, media art, and cyberculture. Bloomington: Indiana University Press.

Ostwald, M. J. (1997). Virtual urban futures. In D. Holmes (Ed.), Virtual politics: Identity \& community in cyberspace (pp. 125-144). London: Sage. 
Pimentel, K., \& K. Teixeira, K. (1993). Virtual reality: Through the new looking glass. New York: McGraw-Hill.

Plant, S. (1996). On the matrix: Cyberfeminist simulations. In R. Shields (Ed.), Cultures of Internet: Virtual spaces, real histories, living bodies. London: Sage.

Quéau, P. (1993). Le virtuel: Vertus et vertiges. Seyssel, France: INA.

Rheingold, H. (1993). The virtual community: Homesteading on the electronic frontier. Reading, MA: Addison-Wesley.

Robins, K. (1996). Cyberspace and the world we live in. In J. Dovey (Ed.), Fractal dreams: New media in social context (pp. 1-30). London: Lawrence \& Wishart.

Schuler, D. (1996). New community networks: Wired for change. New York: ACM Press. Extracts available online at: http://www.scn.org/ip/commnet/ncn.htm

Sfez, L. (2001). Le réseau: Du concept initial aux technologies de l'esprit contemporaines. In D. Parrochia (Ed.), Penser les réseaux (pp. 93-113). Seyssel (France): Champ Vallon, coll. Milieux.

Slouka, M. (1995). War of the worlds: Cyberspace and the high-tech assault on reality. New York: Basic Books.

Smith, M. A., \& Kollock P. (Eds.). (1999). Communities in cyberspace. London: Routledge.

Stone, A. R. (Sandy). (1991). Will the real body please stand up?: Boundary stories about virtual cultures. In M. Benedikt (Ed.), Cyberspace: First steps (p. 81-118). Cambridge, MA: MIT Press.

Tönnies, F. (1992 [1887]). Communauté et société [orig. ed. 1887]. Extracts reproduced in K. Van Meter (Ed.), La Sociologie, coll. Textes essentiels (pp. 195-211). Paris: Larousse.

Tremblay, G. (1998, June). Réseaux de communication, culture et société: Virtualité et matérialité. Paper presented at Politiques et pratiques culturelles : Exploration des liens entre la culture and le changement social, Ottawa, Canada.

Turkle, S. (1995). Life on the screen: Identity in the age of the Internet. New York: Simon \& Schuster.

Weinreich, F. (1997, February). Establishing a point of view toward virtual communities. CMC Magazine. Available: http://www.december.com/cmc/mag/1997/feb/wein.html

Weissberg, J-L. (1996). Internet, un récit utopique. Terminal, 71/72, 7-21.

Weissberg, J-L. (1999). Présences à distance: Déplacement virtuel et réseaux numériques, pourquoi nous ne croyons plus la télévision. Paris: L'Harmattan.

Wellman, B, \& Gulia, M. (1999). Virtual communities as communities: Net surfers don't ride alone. In M. Smith \& P. Kollock (Eds.), Communities in cyberspace (pp. 167-194). London: Routledge.

Wilbur, S. P. (1997). An archeology of cyberspaces: Virtuality, community, identity. In D. Porter (Ed.), Internet culture. New York: Routledge.

Willson, M. (1997). Community in the abstract: A political and ethical dilemma? In D. Holmes (Ed.), Virtual politics: Identity \& community in cyberspace (pp. 145-162). London: Sage.

Wood, J. (1998). Preface: Curvatures in space-time-truth. In J. Wood (Ed.), The virtual embodied: Presence/practice/technology (pp. 1-12). London: Routledge.

Woolley, B. (1992). Virtual worlds: A journey in hype and hyperreality. Oxford: Blackwell.

i[1] Sfez (2001, p. 103). Our translation.

ii[2] This study is to a large extent inductive. Inspired by qualitative methodology, it is based on an exploratory sample of current work in the social sciences, rather than an exhaustive sampling. We have 
attempted to achieve a certain coherence in retaining mostly academically-oriented writing (monographs, chapters in edited books, peer-reviewed articles, conference presentations) which had set out to take stock of the new social spaces issuing forth from the intersection of digital technologies and communication networks as emerging objects of investigation. We believe that, despite of its exploratory nature, our sample is in this sense quite representative of intellectual production in this field.

iii[3] Most citations of French-language texts here are our own translations.

iv[4] Computers offering asynchronous messaging, to which users connect directly via modem. BBSs were successful in Canada and the U.S. due to the flat-rate pricing of local telephony, but their local "enclosure" and drastic limits on the number of users connected simultaneously-each user monopolising a telephone line and modem - were their chief disadvantages in comparison to distributed networks such as Usenet. $\mathrm{v}$ [5] Also founder of software firm Lotus.

vi[6] Sometimes referred to in French using the recently-coined adjective "communautique" (Harvey, 1995). 